\title{
Understanding Clusters toward the Design of Functional Molecules and Nanomaterials
}

\author{
N. Jiten Singh, Eun Cheol Lee, Young Cheol Choi, Han Myoung Lee, and Kwang S. Kim* \\ Center for Superfunctional Materials, Department of Chemistry, Pohang University of Science and Technology, \\ San-31, Hyojadong, Namgu, Pohang 790-784, Korea \\ Received February 1, 2007; E-mail: kim@postech.ac.kr
}

\begin{abstract}
In this account, we highlight the theoretical investigations of various cluster systems comprising of water clusters, $\pi$-containing clusters, and metallic clusters. We illustrate how these investigations help us understand and design structures and properties of nanowires, novel functional ionophores/receptors, and nanomaterials. Many of these theoretically predicted systems have been experimentally realized and some of the predicted structures/properties are left for the future which of course could be promising challenges for experimentalists.
\end{abstract}

\section{Introduction}

A wide variety of atomic and molecular clusters including organic/inorganic/hybrid/metal nanoclusters (such as $\mathrm{H}$ bonded clusters, ${ }^{1,2} \pi$-system-containing clusters, ${ }^{3-5}$ inorganic clusters, ${ }^{6-8}$ and metal clusters ${ }^{9-11}$ ) have been studied experimentally and theoretically. However, it is interesting to note that its practical utility has hardly been seriously considered in theoretical chemistry. We have realized its futuristic potential applications in the development of nanodevices, memory devices, quantum information devices, electric and optoelectronic devices, nanoscale machines, nanovehicles, and nanoscale-targeted drug delivery. Future nanomachines are expected to perform extraordinary functions such as transporting medicine in the human body, conducting operations in and between cells, moving cargo around microfluidic chips, managing light beams, searching for and destroying toxic organic molecules in polluted water, etc.

Understanding the structural and functional properties of these nanomaterials/nanoclusters is of the greatest challenge, since the properties of the components of the nanoclusters change quite significantly with the size, and are in general quite different from the bulk system. Nanomaterials could simply be represented by clusters or aggregates of clusters whose dimension ranges from 0 to 3 dimensional (3-D) structures. Clusters are formed with the aggregation of atoms/molecules by virtue of the competitive and cooperative effect of one or more types of interaction forces. Therefore, understanding clusters vis-à-vis intramolecular/intermolecular forces are important to get insight into the change of structural and functional properties of nanoclusters with respect to the size. Eventually, these investigations are closely related to the advance- ment toward the rational design of novel functional nanomaterials and fabrication of nanodevices. Thus, the state-of-the art computational chemistry and physics approach help us design and invent novel molecular systems possessing desired specific properties toward realization. ${ }^{12-14}$ This would be one of the important missions of computational research in chemistry in the near future.

In this context, we begin our discussion with brief accounts on the salient features of our work on diverse clusters. These investigations not only provide pertinent information useful for nanomaterial design but also highlight some of the important similarities and differences in their physical characteristics. Notable applications of clusters toward the design and investigation of metallic nanowires, endo/exohedral fullerenes/nanotori, nonlinear optical materials, novel ionophores, sensors, molecular nanotubes, and molecular devices are highlighted.

\section{Theoretical Background}

One of the consequences of intermolecular interactions is the formation of clusters which are very important for the theoretical design strategy of functional nanomaterials. ${ }^{15}$ These interactions can be found from the theoretical investigation of various atomic and molecular clusters using diverse methods such as (i) density functional theory (DFT), (ii) Møller-Plesset second-order perturbation theory (MP2), and (iii) coupledcluster theory with single, double, and perturbative triple excitations $[\mathrm{CCSD}(\mathrm{T})]$ with basis sets composed of both polarization and diffuse functions. For large systems, we use pseudopotential plane wave or tight-binding methods. As the systems become larger, Monte Carlo (MC) simulations and molecular dynamics (MD) simulations based on effective pair potentials 


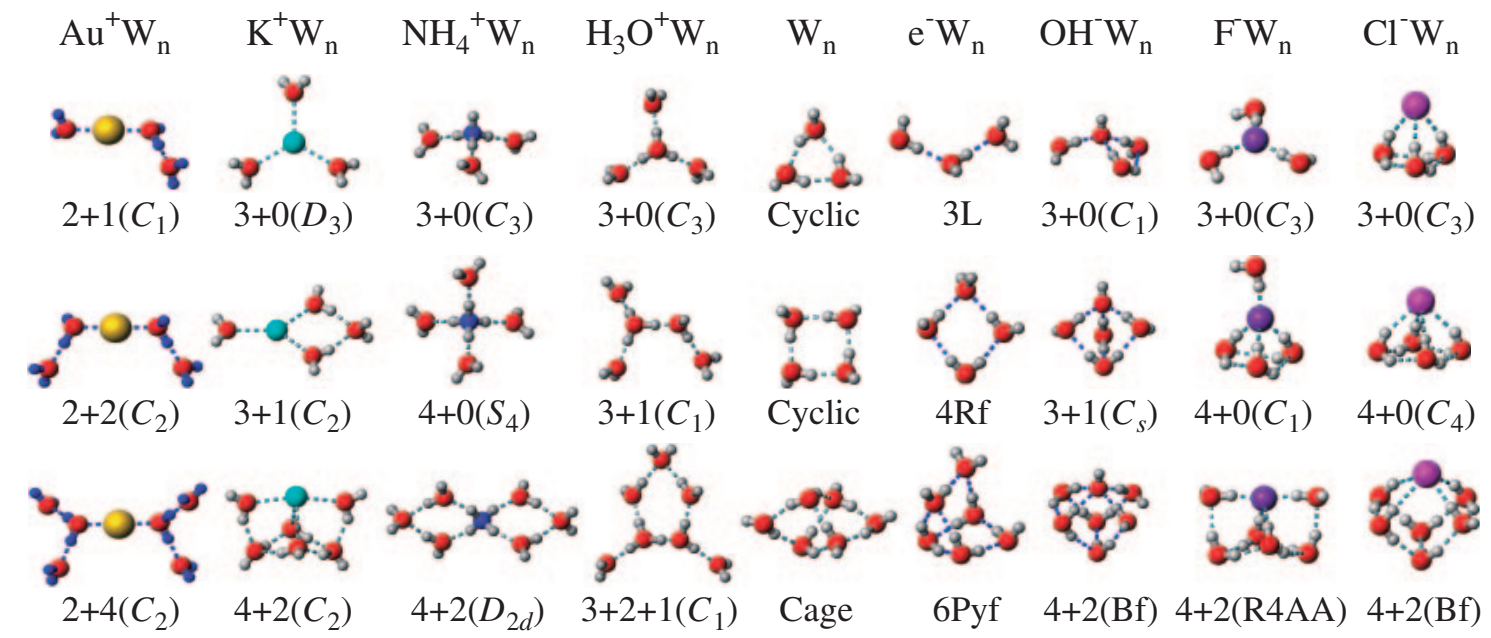

Fig. 1. Structures of water clusters and hydrated cationic/anionic clusters [Refs. 75, 74, 46, 98, 60/61, 104, 93, 89, and 90/91].

(including two-body to multi-body interactions) are carried out. More accurate dynamics studies are studied with ab initio MD (AIMD) simulations.

More specifically, ionic clusters involving with cationic interactions and typical hydrogen bonding are often investigated with DFT methods, because DFT, MP2, and CCSD(T) results are in general consistent. Though cationic clusters can be investigated with somewhat small basis sets, anionic clusters need to be investigated with basis sets including diffuse basis functions. In particular, for systems including excess electrons or highly excited states, very large diffuse basis functions should be included because such an electron can be populated in a very large space. In this regard, the electron correlation effect is important, and so MP2 and $\operatorname{CCSD}(\mathrm{T})$ calculations are needed for the proper description of anionic systems. In the case of $\pi$ systems, the dispersion interaction is very important. Since DFT often fails in describing the dispersion energy in $\pi$ systems, MP2 and $\operatorname{CCSD}(\mathrm{T})$ calculations are required. ${ }^{5}$ However, MP2 tends to overestimate the dispersion energies as the basis set increases. Thus, $\operatorname{CCSD}(\mathrm{T})$ calculations need to be done for accurate description of $\pi$ systems. In the case of metallic clusters, $\operatorname{CCSD}(\mathrm{T})$ results are often between DFT and MP2 results, and the DFT results are closer to the experimental values than the MP2 results. In particular, in this case, the electronic properties of DFT are often better than the $\operatorname{CCSD}(\mathrm{T})$ results, while the MP2 results often fail in near-metallic systems due to somewhat quasi-degenerate states. For molecular assembly based on hydrogen bonding as well as molecular recognition for non-anionic systems, DFT can be employed as a useful approach. However, for the $\pi$ systems and highly anionic systems, the MP2 or even $\operatorname{CCSD}(\mathrm{T})$ results are needed for accurate description.

By investigating the electrostatic interaction, induction, dispersion, and exchange repulsion of the total binding energy, we have utilized the subtle difference among various types of interactions such as hydrogen bonding ${ }^{2,16}$ (normal, weak, strong, ${ }^{17}$ and short strong ${ }^{18-20} \mathrm{H}$-bonds, charged or ionic $\mathrm{H}-$ bonds, etc.), ionic interactions, interactions involving $\pi$ systems $\left(\pi-\pi\right.$ interactions, ${ }^{5,21-31} \pi-\mathrm{H}$ interactions, ${ }^{21-39}$ cation- $\pi$ interactions, ${ }^{40-47}$ anion- $\pi$ interactions ${ }^{48-50}$ ), metallic interactions, ${ }^{51,52}$ and interactions involving quantum species (mole- cule-electron/hole/photon interactions related to electron binding/releasing, ${ }^{53}$ charge-transfer, ${ }^{54}$ and photo-excitation ${ }^{55,56}$ ).

\section{Clusters}

Aqueous Ionic Clusters. Neutral water clusters have been well investigated. ${ }^{57-70}$ With this background, it is useful to examine how the structures and properties of these water clusters are modulated in the presence of cations, anions, protons, electrons, and $\pi$ systems. Ion-dipole interaction is the dominant force for the interaction of water molecules and cations. Hence, as hydrogen atoms of the water molecule are oriented away from both the cation and the oxygen lone pairs interacting with the cation, the water-water H-bonding around the cation is rather suppressed unless the cation (such as $\mathrm{Cs}^{+}$) has large ionic radius. As a result, most of the cationic water clusters, if the ionic size is small, tend to be somewhat spherically hydrated (Fig. 1). ${ }^{71-83}$ On the other hand, in the anion water clusters the contribution of electrostatic interactions is less effective because they have a lower ratio of charge to radius than isoelectronic cations, while the polarization effect becomes significant. In anion-water clusters, ${ }^{84-93}$ the anionwater dipole interaction is suppressed, and the inter-water $\mathrm{H}$ bonding interactions around the anion become important. As the hydrogen atoms point toward the anion, there can be strong repulsions between hydrogen atoms. More importantly, the excess electron needs a large empty space around the anion in which the excess electron can be stabilized by reducing its kinetic energy due to the uncertainty principle. Therefore, a surface-bound non-spherical structure with the excess electron in a large vacant space on the opposite site of the dipole direction tends to be much more stable (Fig. 1). This might be exceptional for the $\mathrm{F}^{-}$ion with strong electronegativity for which the excess electron is strongly bound to $\mathrm{F}^{-}$due to its small ion radius.

While cationic water clusters favour internal structures, anionic water clusters favour surface structures. ${ }^{15}$ The critical difference in the structural preferences of hydrated cation and anion clusters provides an important clue for the design of cation- and anion-specific ionophores and receptors. Indeed, we note that most cation receptors have spherical structures, while almost all anion receptors do not have compact spherical 


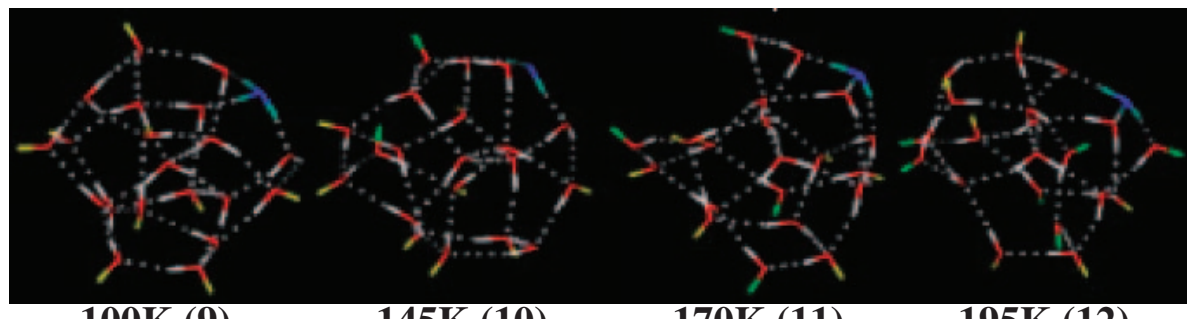

100K (9)

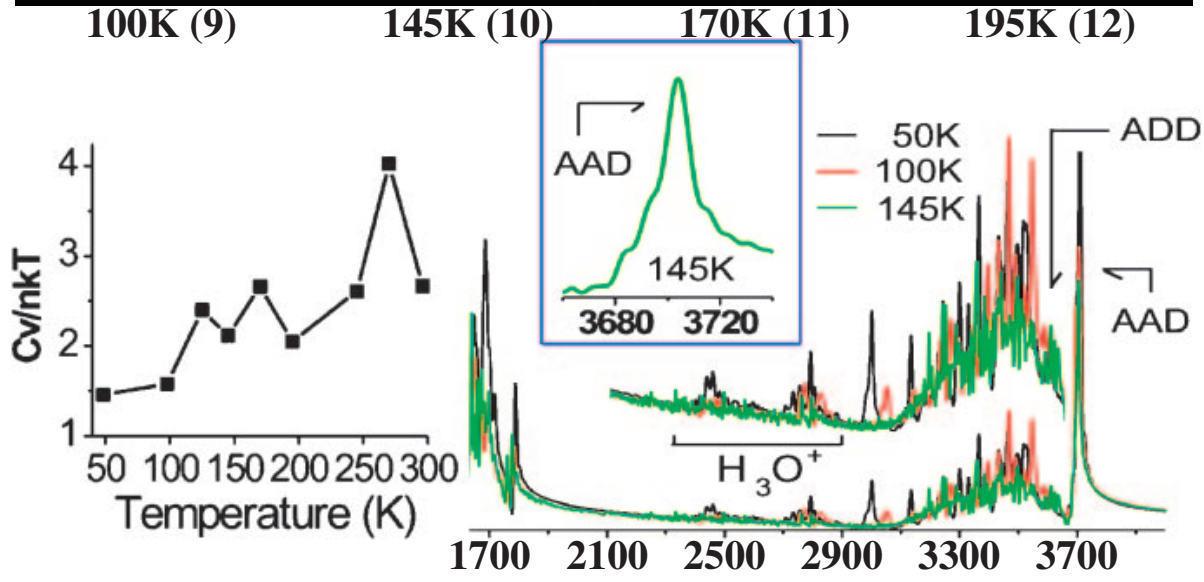

Fig. 2. Temperature-dependent representative structures (number of dangling hydrogen $\left(\mathrm{H}_{\mathrm{d}}\right)$ atoms in parentheses), heat capacity, and power spectra of $\mathrm{H}^{+}\left(\mathrm{H}_{2} \mathrm{O}\right)_{21}$ at varying temperatures [AAD $\mathrm{H}_{\mathrm{d}}$ 's: yellow color; AD-type $\mathrm{H}_{\mathrm{d}}$ 's: green, where A: acceptor and $D$ : donor]. Despite the presence of configurations with an extra AD-type $\mathrm{H}_{\mathrm{d}}$ at $145 \mathrm{~K}$, the AD peak does not appear as the AD-type $\mathrm{OH}$ keeps on changing its nature (toward the ADD and AAD types) during simulations. The peaks associated with $\mathrm{H}_{3} \mathrm{O}^{+}$at low temperature are nearly lost at $125 \mathrm{~K}$ and disappeared completely at $150 \mathrm{~K}$ and onwards [Ref. 97].

structures but have a vacant space around the anion binding site without full coordination. However, as the temperature increases, the hydration structure tends to be more spherical due to the entropy effect.

It would be interesting to investigate the protonated water clusters $^{71,94-98}$ and electron-binding clusters, ${ }^{99-110}$ because both proton and an excess electron are quantum species which cannot be properly treated classically like ordinary cations and anions. Both protonated water clusters and electron-binding clusters form surface structures because the surface proton or electron enhances the stability of the clusters by maximizing the polarization effect. The magic $\left[\mathrm{H}^{+}\left(\mathrm{H}_{2} \mathrm{O}\right)_{21}\right]$ and antimagic $\left[\mathrm{H}^{+}\left(\mathrm{H}_{2} \mathrm{O}\right)_{22}\right]$ protonated water clusters are found to have surface structures according to ab initio molecular dynamics simulations (Fig. 2). ${ }^{97}$ The proper assignment of their spectral data demanded the thermal and dynamic effect consideration. ${ }^{97,98}$ The excess electron-binding water clusters of small size show the surface structures, and the difference between the magic and anti-magic clusters arises from the relative stability of neutral water clusters because the neutral water clusters show the characteristic features with respect to the size, while the stability of the anionic water clusters changes smoothly (i.e., monotonously). ${ }^{104}$

Clusters of Dissociated Acids, Bases, and Salts. Investigation of aqueous clusters of acids, ${ }^{111-115}$ bases, ${ }^{116-118}$ and salts ${ }^{119-123}$ helps us understand the dissociation phenomena of these molecules. Upon dissociation, both cations and anions are simultaneously present in the system. In the case of hydrogen halides, we have shown that in the presence of four water molecules, the dissociated structures of hydrogen chloride, bromide, and iodide are more stable than the corresponding undissociated ones (Fig. 3), while undissociated structures of hydrogen fluoride is more stable than the dissociated ones even when they are hydrated by over ten water molecules. ${ }^{115} \mathrm{LiOH}$, $\mathrm{NaOH}, \mathrm{KOH}, \mathrm{RbOH}$, and $\mathrm{CsOH}$ require 7, 6, 6, 5, and 4 water molecules, respectively, for dissociation (Fig. 3) upon the consideration of the global minimum structures. ${ }^{118}$ For salt water clusters $\left[\mathrm{NaX}\left(\mathrm{H}_{2} \mathrm{O}\right)_{n}\right](\mathrm{X}=$ halides $),{ }^{119}$ we find that the dissociated structures are first found with $n=5$ for $\mathrm{X}=\mathrm{Br} / \mathrm{I}$, though these structures are slightly higher in energy than the global minimum-energy structure. In the case of hexa-hydrated sodium halides, the global minimum-energy structures are found to be dissociated $(\mathrm{X}=\mathrm{F} / \mathrm{I})$ or partially/half dissociated $(\mathrm{X}=\mathrm{Cl} / \mathrm{Br}$ ) (Fig. 3). Similar trend was observed in the case of $\mathrm{CsF}$ dissociation phenomena. ${ }^{120}$ This understanding would be useful for the design of desalinating receptors.

$\boldsymbol{\pi}$-Clusters. Clusters containing $\pi$ systems are bound with weak interactions. Therefore, accurate description is required with very high levels of theory. The $\pi$-containing clusters can be broadly classified into nonpolar $-\pi, \mathrm{H}-\pi, \pi-\pi$, and $\pi$-ion (cation/anion) clusters depending on the countermolecule interacting with the $\pi$-system. We provide a brief account on clusters of the above-mentioned types.

(1) In the case when the countermolecule is either a rare gas atom or a nonpolar molecule, dispersion interactions dominate for the formation of nonpolar- $\pi$ clusters. ${ }^{124}$

(2) A combination of electrostatic and dispersion interactions governs the interaction energy for the formation of $\mathrm{H}-$ $\pi$ clusters (Fig. 4) as the countermolecule is polar (water, methanol, and Lewis acids). ${ }^{38,39}$ Unlike in the case of ionwater clusters, there are little changes in the gross structural features of the water clusters in their complexed states with 

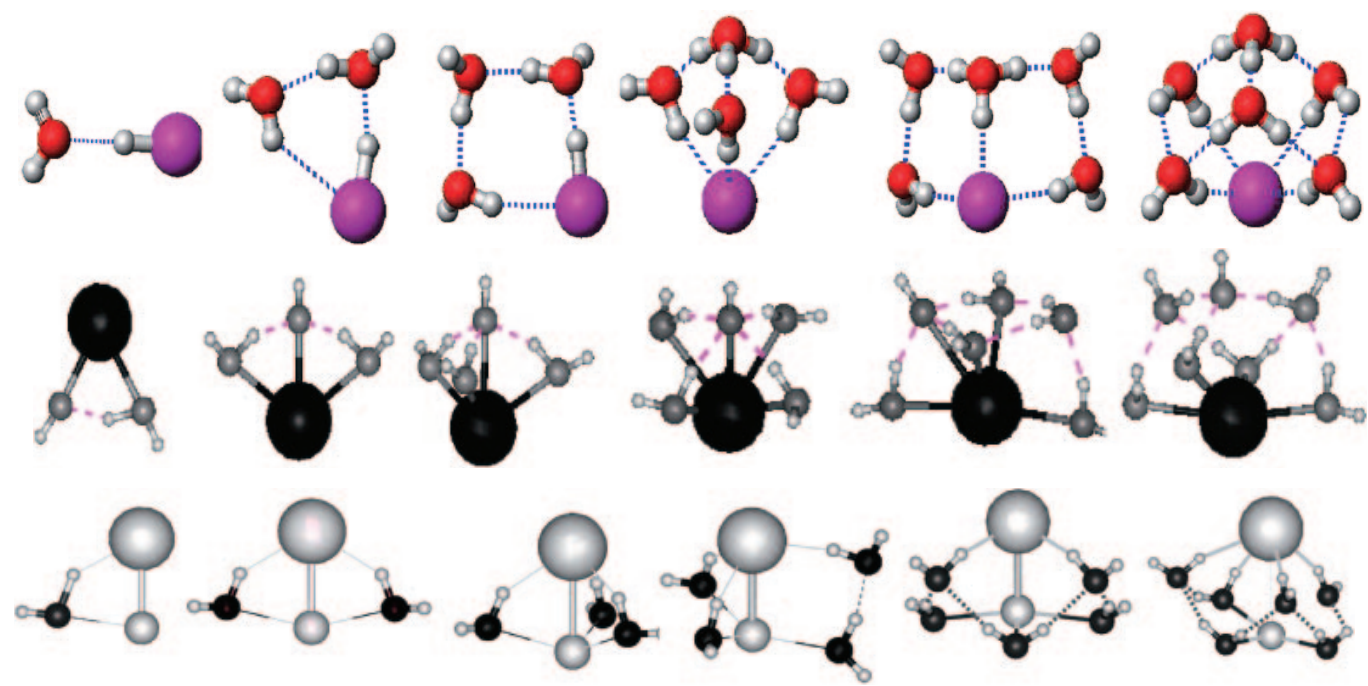

Fig. 3. Lowest-energy structures of hydrated acids (top: $\mathrm{HCl}$ ) [Ref. 114], bases (middle: $\mathrm{KOH}$ ) [Ref. 118], and salts (bottom: NaI) [Ref. 119].

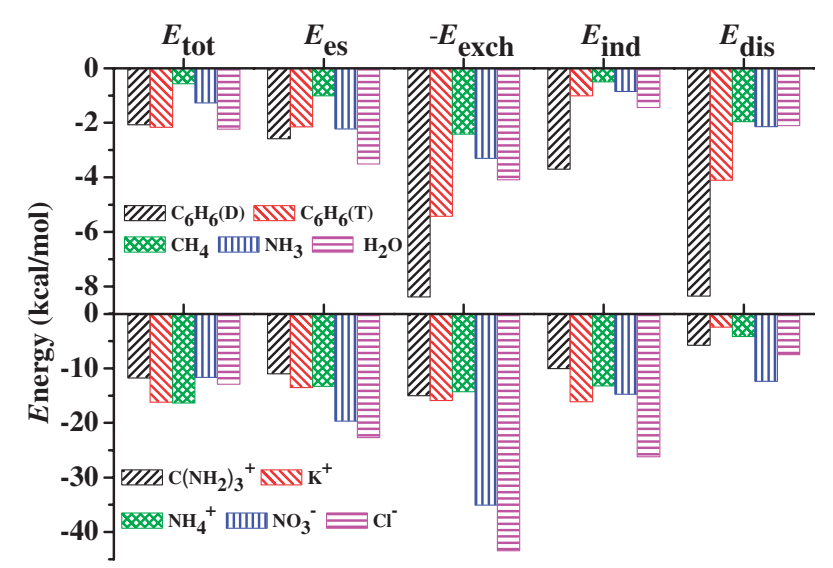

Fig. 4. Comparison of $\pi-\pi$ and $\pi-\mathrm{H}$ interaction components [Refs. 31 and 39] and comparison of cation- $\pi$ and anion- $\pi$ interactions [Refs. 46 and 48]. Each system denotes the interaction by the benzene. (D) and (T) denote displaced-stacked and T-shaped, respectively. Each energy component means tot: total, es: electrostatic, exch: exchange repulsion, ind: induction, and dis: dispersion.

the $\pi$ systems because the interactions existing between water molecules in these clusters are much stronger than the $\pi$ interactions between the water clusters and the $\pi$ systems. ${ }^{125,126}$ Another interesting finding from our calculations of the benzene interacting with Lewis acids (halides of aluminium, boron, and hydrogen $)^{127-129}$ was that the interaction energies are large $\left(8-15 \mathrm{kcal} \mathrm{mol}^{-1}\right)$ among neutral $\pi$ interactions. The importance of the proposed $\pi$-Lewis acid interactions in understanding the nature of catalysts and ionic liquids was highlighted by Olah et al. ${ }^{130}$ and Seddon and Earle. ${ }^{131}$

(3) The $\pi-\pi$ interactions are one of the fascinating noncovalent interactions in the sense that the negatively charged and diffuse electron clouds of the $\pi$ systems exhibit an attractive interaction. The experimental estimates of the interaction energy of the benzene dimer is $\approx 2 \mathrm{kcal} \mathrm{mol}^{-1}$, and the Tshaped and parallel-displaced conformation are the most stable, but the former would be slightly more stable. ${ }^{132-135}$ However, it should be noted that the isolated benzene dimer is highly fluxional and can coexist in any of the three structural forms as T-shaped, stacked, and displaced-stacked form. The substituent effect changes the conformation significantly because of the subtle energy difference between the T-shaped and displaced-stacked structures. For example, the interaction of benzene and quinone/hydroquinone could be controlled for the interconversion between T-shaped and displaced-stacked conformation with the reduction/oxidation of the quinone/ hydroquinone moiety in the molecular system.

(4) In the context of nanomaterial design, cation $-\pi$ interactions ${ }^{40-47}$ are important interactions involving $\pi$ systems. Here, electrostatic and induction energies dominate the interaction energy. In the case of $\pi$-organic cation complexes, the magnitudes of the electrostatic and induction energies are much smaller than in the $\pi$-alkali metal cation complexes, and the contribution of dispersion energies are significant (Fig. 4) ${ }^{44,45}$ It is worthwhile to mention that in cation- $\pi$ systems the magnitude of the electrostatic energy is much less than in cation-water cluster systems, while the dispersion energy is much larger. This marked difference is due to the fact that the more localized donor lone pair of the water oxygen atom (in contrast to the diffuse electron cloud of the $\pi$ system) interacts with the cation, giving a much larger electrostatic contribution in the total energy. However, the larger dispersion energy of the cation $-\pi$ systems plays an important role in designing receptors in non-polar solvents.

(5) For anion- $\pi$ clusters, ${ }^{48-50}$ the total interaction energies are comparable to those corresponding to cation $-\pi$ clusters (Fig. 4) ${ }^{48}$ However, the magnitude of exchange-repulsion energy is significantly large due to the increased repulsion between the electron density of an aromatic ring and the electron density of an anion. This repulsion is compensated by the increase in electrostatic and induction energies. When the anion is organic moiety, the dispersion energy is very significant.

Metallic Clusters. Theoretical investigation of the metal clusters, in particular for the noble metals, depends on the 
$\mathrm{Au}_{\mathrm{n}}$

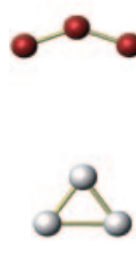

$\operatorname{Ag}$
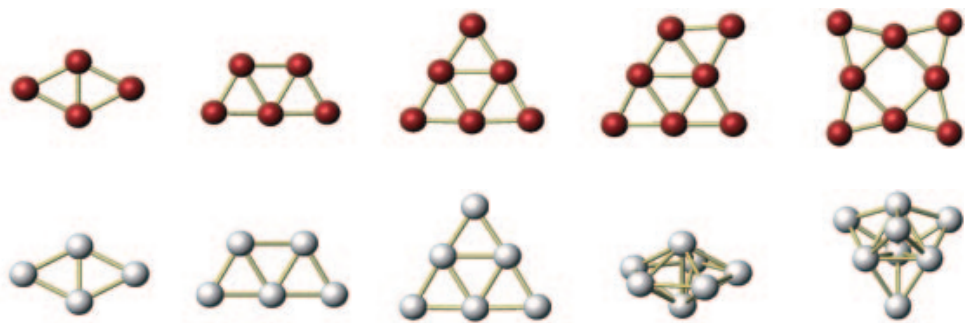

$\mathrm{AuAg}-1$
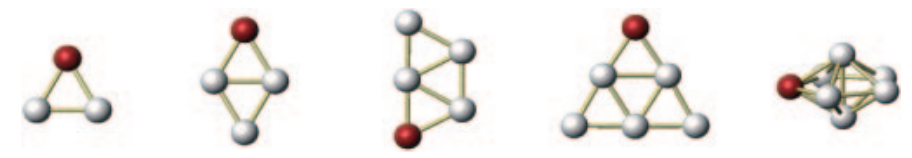

Fig. 5. Lowest-energy structures of $\mathrm{Au}_{n}, \mathrm{Ag}_{n}$, and $\mathrm{AuAg}_{n-1}$ along with the electron correlation diagram of $\mathrm{Au}_{2}, \mathrm{Ag}_{2}$, and $\mathrm{AuAg}$ [Refs. 11 and 136].
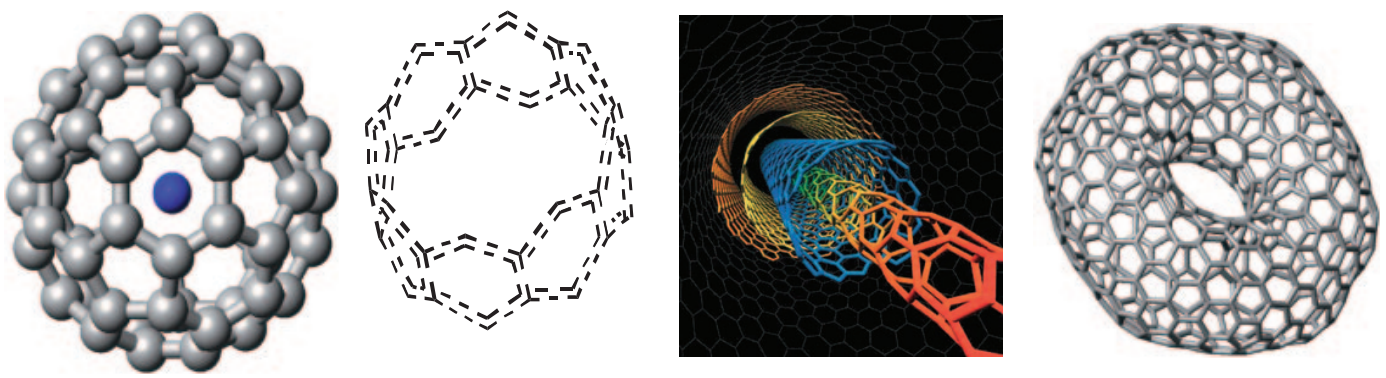

Fig. 6. Spin-containing endohedral fullerene $\mathrm{N} @ \mathrm{C}_{60}$ [Ref. 140], cyclacene as a shortest carbon nanotube [Ref. 142], extracted inner shells from an ultralong multi-walled carbon nanotube [Ref. 143], and nanotori [Ref. 145].

ability of theoretical method (such as the relativistic effect) to describe metallic interactions. Investigation of the metal clusters and metal alloy clusters are of interest because they serve as protoptypical models of nanoelectrodes, nanowires, etc. which exhibit unique electronic, magnetic, optical and mechanical properties as a result of the appearance of the quantum effects in such small clusters. In particular, it is interesting to investigate the gold-silver alloying effect. ${ }^{136}$ Since the $6 \mathrm{~s}$ orbital energy of $\mathrm{Au}$ is almost as low as $5 \mathrm{~d}$ orbitals, the relativistic effect-driven strong s-d hybridization in Au favours 1-D and 2-D structures in the case of small gold clusters (Fig. 5). Thus, gold shows high ductility. On the contrary, silver clusters larger than the hexamer prefer to exist as 3-D structures with spherical coordination because the valence orbitals are predominantly of the s-type (Fig. 5). This preference in coordination reflects itself in the location of the $\mathrm{Au}$ and $\mathrm{Ag}$ atoms in the corresponding binary clusters of gold and silver, with the Au atoms being located on the boundary, while Ag atoms are generally located in the inner side (Fig. 5). Since the Ag-5s orbital is much higher in energy than the Au6s orbital energy, the partial charge transfer from $\mathrm{Ag}$ to $\mathrm{Au}$ takes place in gold-silver binary clusters. This partial charge transfer in the binary system resulted in electrostatic energy gain for the binary $\mathrm{Au}_{m} \mathrm{Ag}_{n}$ cluster over pure gold and silver clusters. Thus, it is responsible for the formation of alloys.

\section{Functional Molecules, Receptors, and Nanomaterials}

So far we have discussed the structure, energetics, and spectra of various clusters. The exciting things about the study of these clusters are their relevance toward the design and understanding of the fascinating world of "nano." The apparent changes of the functional properties of the nanomaterials depending on the size, structure, and dimension, due to the emergence of the quantum effects, demand high level of theoretical calculations for proper explanation. Despite that there are many sophisticated instruments capable of observing the phenomena at the nanometer scale, the limitations of the experimentalists are the incorporation of the quantum effect in the intuition-based design approach and the difficulty in explaining observed phenomena. This is the reason why the calculation methods based on quantum mechanics emerge to play an important role in investigating functional nanomaterials and become an inevitable tool for the design approach. In the following section, we will discus selected examples of the materials we have designed. Many of them are experimentally realized, showing the functional properties we had predicted based on our calculations.

Carbon-Based Nanomaterials: Fullerenes, Carbon Nanotubes, and Nanotori. Carbon-based nanomaterials undergoes profound changes in its physical and chemical characteristics upon the external perturbations. Apart from electrochemical, photonic, magnetic, or electrical means of external perturbations, cations, or neutral atoms are also simple perturbations. In this context, the magnetic properties of exohedral fullerenes of metal fullerides $\left(\mathrm{A}_{x} \mathrm{C}_{60}, \mathrm{~A}=\right.$ alkali metal, etc. $)^{137-139}$ and the spin properties of endohedral fullerenes (A@ $\left.\mathrm{C}_{60}, \mathrm{~A}=\mathrm{N}, \mathrm{P}, \mathrm{As}, \mathrm{O}, \mathrm{S}\right)^{140,141}$ (Fig. 6) are particularly interesting. Our calculations indicated that the interaction 
observed in the case of $\mathrm{N} @ \mathrm{C}_{60}$ is predominantly dispersive in nature. These systems are interesting because endohedral fullerenes containing paramagnetic atoms could be utilized to design quantum information devices.

The shortest nanotube would be beltene-type organic nanotube where hydrogen atoms would be attached to the edge carbon atoms for the stabilization of nanotube (Fig. 6). This nanotube shows intriguing phenomena such as even-odd characteristics for the band gap and single-triplet energy difference. ${ }^{142}$ In a while, using atomic force microscope we have recently engineered ultralong multi-walled carbon nanotube allowing the exposure of the innermost single-walled carbon nanotubes $\left(\approx 0.4 \mathrm{~nm}\right.$ diameter) (Fig. 6). ${ }^{143,144}$ This was conceptually possible because the $\pi-\pi$ interaction is found to have a very flat potential based on very high level of theory. We observed that the outer hollowed-out nanotubes show either metallic or semiconducting character, while the innermost single-walled carbon nanotubes with small diameter exhibit predominantly metallic transport properties. The observed gate-dependent nonlinear current $(I)$-bias voltage $(V)$ characteristics of centimeter-long CNTs would bring about a potential application of these CNTs as multifunctional electronic devices.

Another important carbon-based material alongside the fullerenes and CNTs is the carbon-nanotori (Fig. 6). ${ }^{145-147}$ Our theoretical investigation on the structures and electronic properties of various nanotories showed that smallest nanotori exhibit interesting metal, semiconductor, and insulator characteristics depending on nanotube building blocks. ${ }^{145}$

Nanowires/Nanoelectrodes: Ferromagnetic Wires and Quantum Conductance. Many of the nonmagnetic metals in bulk appeared to be ferromagnetic at low dimensions. With the advancement on the experimental techniques to fabricate the metal nanowires, ${ }^{148-152}$ the possibilities of incorporating them in the futuristic electronic/optoelectronic devices, quantum devices, magnetic storage, nanoprobes, and spintronics are anticipated. We have also investigated the 1-D, 2-D, and 3-D systems of all the early transition metals (groups 3-7) ${ }^{153}$ and most transition metals (groups 8-12). ${ }^{154-156}$ Among the early transition metals, elementary low-dimensional systems of groups 3 and 4 prefer ferromagnetic ordering, with only Hf preferring to stay nonmagnetic as in the bulk. Antiferromagnetic ordering is preferred by elementary low-dimensional systems of transition metals of groups 5 to 7 . Our calculations are in good agreement with the recently reported nanowires of $\mathrm{Nb}, \mathrm{Mo}, \mathrm{Ti}$, and W. ${ }^{148-150}$ Magnetic linear chains of Sc, Ti, $\mathrm{Zr}$ (ferromagnetic in nature), and $\mathrm{Cr}$ and $\mathrm{Re}$ (antiferromagnetic in nature) are predicted to offer relative ease of formation. In the case of transition metals in group 8, only $\mathrm{Fe}, \mathrm{Co}$, and $\mathrm{Ni}$ show the ferromagnetism in the bulk, while many elements in 2-D show ferromagnetism; in particular, all elements except for Ir in group 8 are predicted to be ferromagnetic in 1-D. Indeed, our results are in agreement with the recent experimental observation that $\mathrm{Pd}$ and $\mathrm{Co}$ nonowires are ferromagnetic. ${ }^{151,152}$ 1-D chains of $\mathrm{Fe}, \mathrm{Co}, \mathrm{Ni}$, and $\mathrm{Pd}$ are found to have one kind of carriers available for conduction at the Fermi energy level $\left(E_{\mathrm{f}}\right)$. This suggests the applicability of these nanowires for spintronics.

Recently, we have investigated the pathway for the thinning process identifying the "magic structures" that the silver nano-
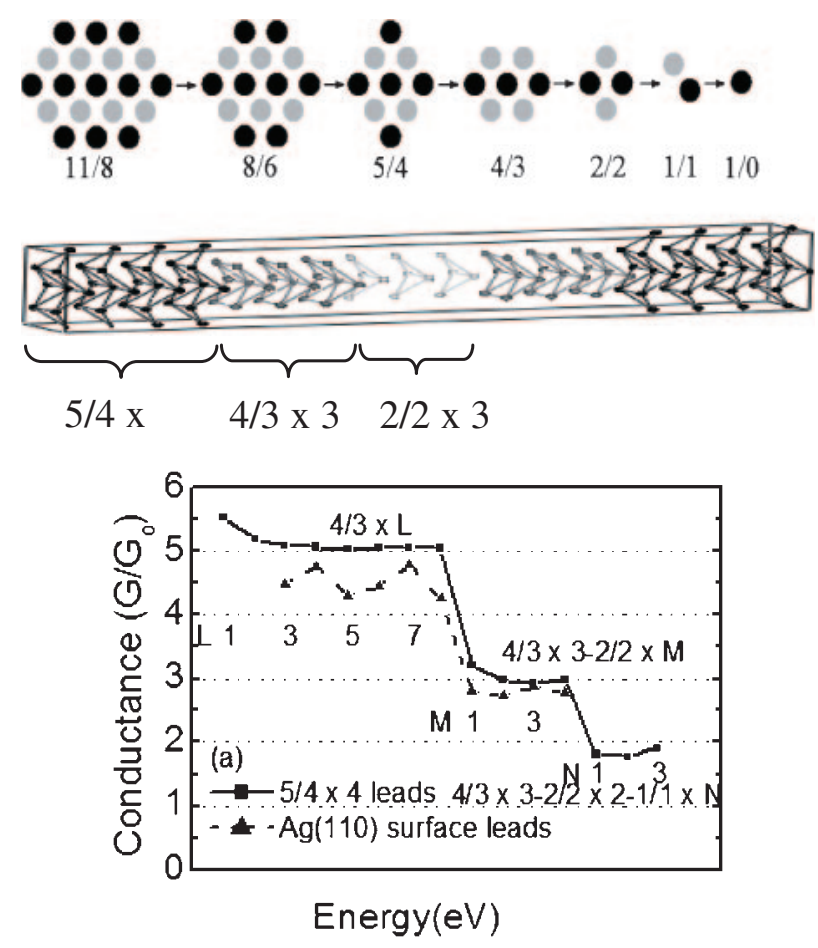

Fig. 7. Magic numbers for $\mathrm{Ag}$ nanowires for the thinning process (changes in cross section) and the fractional quantum conductance (Reproduced by permission of American Physical Society [Ref. 157]).

wires would adopt before breaking down. ${ }^{157}$ Considering the energetics of various $\mathrm{Ag}$ structures, we conclude that the simplified pathway of thinning process for $\mathrm{Ag}[110]$ nanowires would be from $11 / 8$ to $8 / 6$ to $5 / 4$ to $4 / 3$ to $2 / 2$ to $1 / 1$ to $1 / 0$ (Fig. 7). On the basis of conductance calculations visà-vis the structure of transient nanowires, the puzzling experimental observation of fractionally quantized conductance values is explained by considering the existence of mixed structures for thin nanowires (Fig. 7).

Ionophores and Chemical Sensors. Various receptors showing either cation recognition ${ }^{158-162}$ or anion recognition ${ }^{163-180}$ have been synthesized and charcterized in the past decades. Despite these achievements, further research efforts are required to address the issues related to the selective recognition of anion/cation in real life samples for the environmental and biological use. The design strategy is complicated because the affinity and selectivity have to be displayed in the presence of a number of competing factors like counter ions, solvents, etc. Nevertheless, subtle differences in the binding of cation/anion with water molecules, $\pi$-systems can effectively be utilized toward the design of experimentally viable receptors which can selectively recognise the ion of interest.

We designed tripodal-based receptors for the selective recognition of the ammonium cation $\left(\mathrm{NH}_{4}{ }^{+}\right)$against the potassium cation $\left(\mathrm{K}^{+}\right)$of nearly equivalent size. ${ }^{161,162}$ Various benzene-based tripodal systems with various binding moieties (pyrazole, dihydro-pyrazole, oxazole, dihydro-oxazole, imidazole, dihydro-imidazole) were investigated. ${ }^{161}$ Host 1 having dihydro-imidazole moiety (Fig. 8) and its derivative with $N$ methyl-substituted dihydro-imidazole showed best selectivity 


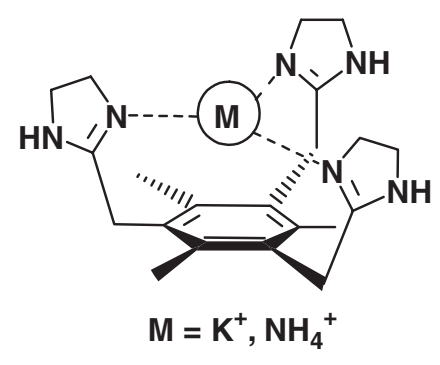

1

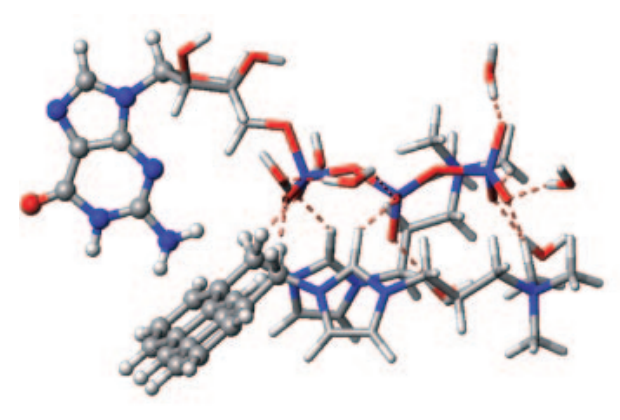

4

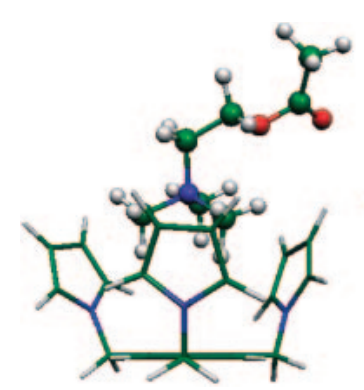

2

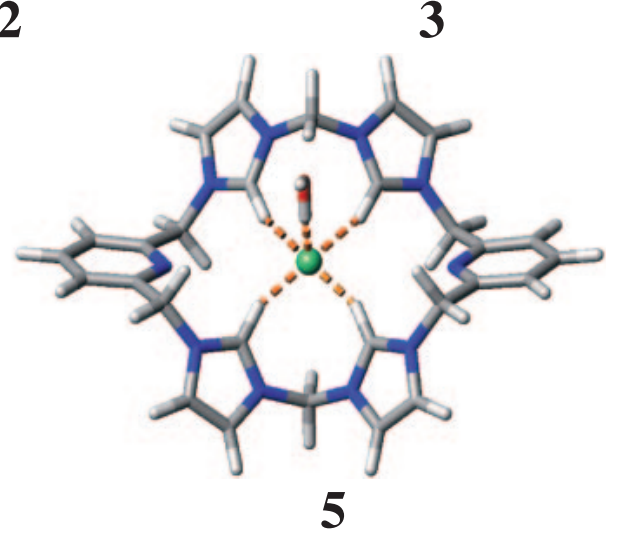

Fig. 8. Tripodal receptors complexed with $\mathrm{NH}_{4}+$ (1) [Ref. 161], acetylcholine (2) [Ref. 162], $\mathrm{Cl}^{-}$(3) [Ref. 171], and fluorophor receptor for GTP (4) [Ref. 178], and calix[4]imidazolium[2]pyridine receptor for $\mathrm{F}^{-}$(5) [Ref. 180].

for $\mathrm{NH}_{4}{ }^{+}$over $\mathrm{K}^{+}$. Even though the $\pi$-cation interaction for $\mathrm{NH}_{4}{ }^{+}$and $\mathrm{K}^{+}$are nearly similar in these receptors, we took the advantage of the coordination number of these cations (4 for $\mathrm{NH}_{4}{ }^{+}, 6$ for $\mathrm{K}^{+}$); thereby the solvent effect dramatically lessens the binding affinity of $\mathrm{K}^{+}$to the host. We extended the concept to the design of host $\mathbf{2}$ which have higher affinity and selectivity for acetylcholine over $\mathrm{NH}_{4}{ }^{+}$utilizing enhanced dispersion interactions and diminished ionic interactions. ${ }^{162}$ This was achieved by replacing the imidazole/pyrazole arms of the $\mathrm{NH}_{4}{ }^{+}$receptors by pyrrole as in host 2 (Fig. 8). 2 showed strong binding affinities for acetylcholine with much better selectivity over $\mathrm{NH}_{4}{ }^{+}$which was experimentally confirmed based on the measurements using ion-selective electrode in water.

Since anions are more polarizable and hence more susceptible to polar solvents than cations, the solvent effect is crucial for the design approach of anion receptors. Among many possible binding moieties available for the anion binding, we have been more interested on the imidazolium moiety which can provide the $(\mathrm{C}-\mathrm{H})^{+} \ldots \mathrm{X}^{-}$ionic hydrogen bonding involving the dominating charge-charge electrostatic interaction. This ionic hydrogen bonding by the imidazolium moieties is stronger than the $\mathrm{NH}$... $\mathrm{X}^{-}$hydrogen bonding of pyrrole and urea moieties. Thus, utilization of such ionic hydrogen bonding improves the binding affinity for the anion. Based on ab initio calculations, highly selective imidazolium-based anionophores have been designed ${ }^{171-180}$ and synthesized.

Imidazolium tripodal receptor 3 (Fig. 8) which has nitro substitution on the imidazolium moiety enhanced the strengh of the $(\mathrm{C}-\mathrm{H})^{+}$... anion interaction as compared to the unsubstituted counterpart due to the enhanced dipole-charge interaction. ${ }^{171,172}$ Fluorescent photoinduced electron transfer (PET) chemosensor for the recognition of pyrophosphate had also been designed and synthesized. ${ }^{173-177}$ This fluorescent study with anions shows the pyrophosphate-induced maximal PET quenching effect. Recently, we have extended our research effort toward the mechanistic study of receptor 4 (Fig. 8) (trimethyl[4-(3-methylimidazol-1-ium)butyl]ammonium substituted at 1,8 anthracene position) which acted not only as a potential fluorescent chemosensor for GTP in $100 \%$ aqueous solution ( $\mathrm{pH} 7.4,10 \mathrm{mM}$ HEPES) but also could differentiate the biologically important phosphates (GTP and ATP). ${ }^{178} \mathbf{4}$ showed the chelation-enhanced fluorescence quenching effect for GTP, whereas it displayed a chelation-enhanced fluorescence effect for ATP, ADP, and AMP. The difference in the unique mode of interaction of GTP and ATP with 4, where the nucleic base of $\operatorname{GTP}(\pi-\mathrm{HN}$ interaction $) / \mathrm{ATP}(\pi-\mathrm{HC}$ interaction) forms a $\mathrm{T}$-shape interaction via strong $\pi-\mathrm{H}$ interaction with the central ring of the anthracene moiety, gave us the explanation of the selectivity of $\mathbf{4}$ toward GTP.

The quinoxaline imidazolium receptors showed the characteristic charge-transfer peak at $\approx 500 \mathrm{~nm}$ in the fluorescent spectra upon binding with pyrophosphate/acetate; however, similar excimer peaks appear at $\approx 430 \mathrm{~nm}$ with other anions. ${ }^{179}$ The rapid charge transfer in the excited state was observed from the quinoxaline moiety to the deprotonated imidazolium moiety as the binding with pyrophosphate/acetate formed a deprotonated complex where the imidazolium hydrogen transferred to pyrophosphate/acetate.

Calix[4]imidazolium[2]pyridine, 5 (Fig. 8) showed high affinity and selectivity for the fluoride anion due to the unique $1: 1$ binding mode of interaction compared to $1: 2$ binding profile with other halide anions. ${ }^{180}$ The calculated structure of the most stable form of $\mathbf{5}$ with $\mathrm{F}^{-}$was in good agreement with that 

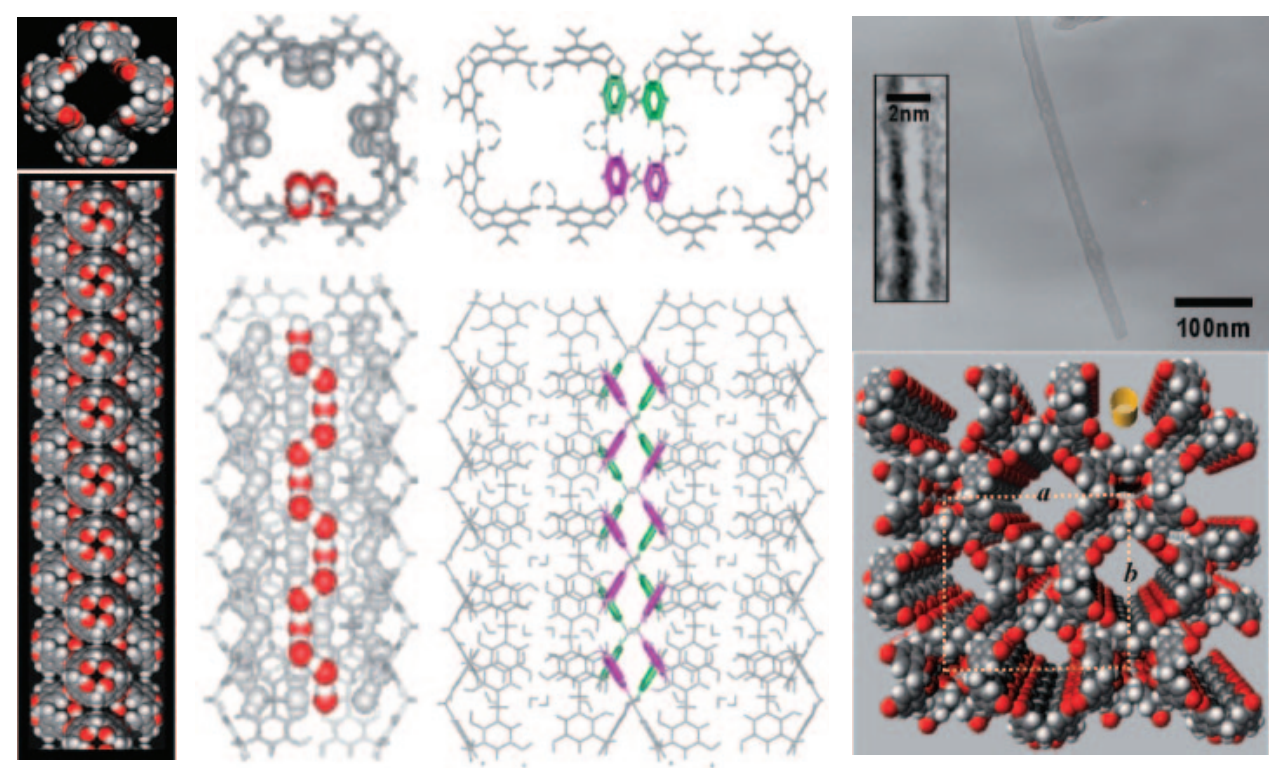

Fig. 9. Calculated structures (binding energy in $\mathrm{kcal} \mathrm{mol}^{-1}$ at the $\mathrm{B} 3 \mathrm{LYP} / 6-31 \mathrm{G}^{*}$ level) of $n$-oligomers (dimer, trimer, tetramer, hexamer, octamer, and polymer) of CHQ in the presence of water (first and second lines), and structure of CHQ nanotubes: a single nanotube, one-dimensional H-bond relay vs. intertubular $\pi-\pi$ stacking, high-resolution electron microscpe image of nanotubes, and X-ray structure of nanotubes (Reproduced by permission of American Chemical Society [Refs. 185 and 187]).

of the crystal structure in which $\mathrm{F}^{-}$was captured at the center of the macrocycle. If we compare this interaction mode with the $\mathrm{F}^{-}\left(\mathrm{H}_{2} \mathrm{O}\right)_{5}$ cluster structure, we may say that the four water molecules at the base of the cluster has been replaced by four imidazolium moieties, whereas the top water molecule represents the solvent affect on the binding of $\mathrm{F}^{-}$to $\mathbf{5}$.

Both collarenes and beltenes ${ }^{181}$ exhibit large binding affinities and high selectivities for metal cations. One of the interesting features of the $[n]$-beltenes complexing with alkali metal cations was that the change in the selectivity order toward an alkali metal cation was correlated with the changes in the size of the beltene cavity size. In a while, [12]collarene exhibits a pronounced binding selectivity for tetramethylammonium and acetylcholine. We have designed various amphi-ionophores with cyclopeptides. ${ }^{182}$ The concept of binding either an anion or a cation by the conformational changes of the receptor has been experimentally realized. ${ }^{183,184}$

Organic Nanotubes. There are several advantages of using hydrogen bonds to design nanomaterials, and in particular, organic nanotubes, because these nanotubes have potential applications as artificial biological channels, drug delivery systems, nano-chemical reactors, etc. ${ }^{185-187}$ An interesting aspect of self-assembling organic nanotubes from non-tubular units of calix[4]hydroquinone (CHQ), a reduced form calix-4-quinone (CQ), was that the theoretical design preceded and was done in parallel with the actual experiment of synthesis and investigation of the X-ray structure. ${ }^{185}$ Upon investigating various possible combinations of the assembled structures of CHQ for dimer, trimer, tetramer, hexamer, and octamer in the absence of water, we observed that the most stable form is the hexamer. However, in the presence of water, the octamer form is the most stable structure where dangling $\mathrm{H}$ atoms of $\mathrm{CHQ}$ s form HQ-(water-HQ-HQ- $)_{n}$-water chains. ${ }^{187}$ As the strength of 1 -D short $\mathrm{H}$-bonding interaction $\left(\approx 10 \mathrm{kcal} \mathrm{mol}^{-1}\right)^{17}$ is stronger than the strength of the $\pi-\pi$ stacking interaction, the assembling along the 1-D short $\mathrm{H}$-bond relay is much more favorable. In experiment, the CHQ tubes assembled to form long tubular structures. This in turn, formed bundles with intertubular $\pi-\pi$ stacking interactions, resulting in crystals with wellordered 2-D arrays of pores. A needle-like nanotube bundle exhibits the infinitely long one-dimensional H-bonding network between hydroxy groups of CHQs and water molecules along with well-ordered intertubular $\pi-\pi$ stacking pairs (Fig. 9).

The solvent accessible surfaces of the CHQ nanotube indicated the possibility that long arrays of metallic or non-metallic atoms could be supported by the pores if it could be introduced into the pore systematically through the process of the self assembly. Our theoretical investigation of the binding situations of neutral and cationic transition metals with the redox system of hydroquinone and quinone predicts that due to synergetic interactions, silver and gold are very efficient metals for one-dimensional (1D) nanowire formation in the selfassembly process, platinum and mercury favor both nanowire/nanorod and thin film formation, while palladium favors two-dimensional (2D) thin film formation. ${ }^{188}$

Nanomechanical Devices and Non-Linear Optical Switches. The strategy for the design of nanodevices is to harness the subtle changes in the $\pi$-electron densities of a quinone moiety as a result of changes in the electronic environment. Quinones are particularly suited for this endeavour because their electronic characteristics can be electrochemically or photochemically controlled. Based on a theoretical investigation of the conformational characteristics of $p$-benzoquinone-benzene complexes, we found that the energy difference between the stacked and edge-to-face conformations of cyclophane molecules is substantial. Thus, the subtle control of the conformational characteristics of 2,11-dithio[4,4]metametaquinocyclophane and 2,11-dithio[4,4]metametahydroquinocy- 


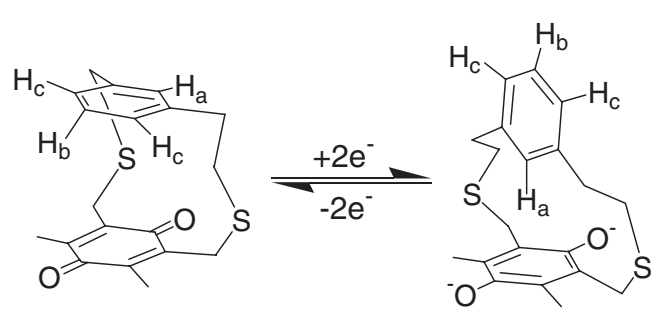

Fig. 10. Molecular flipper as a nano-mechanical devices (Reproduced by permission of American Chemical Society [Ref. 189]).

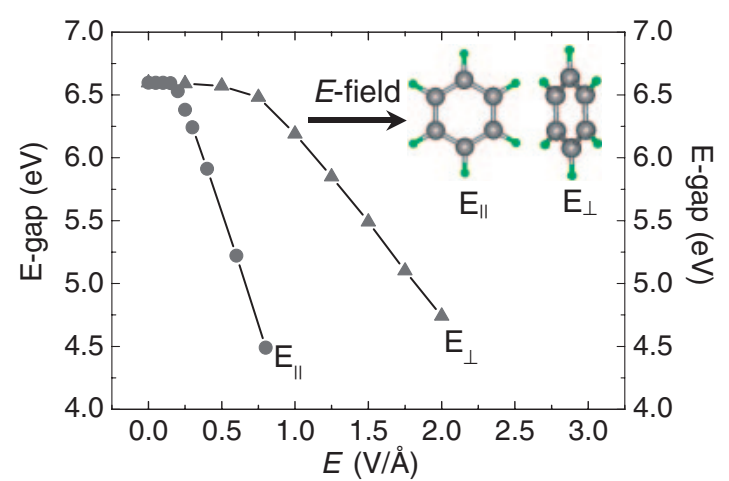

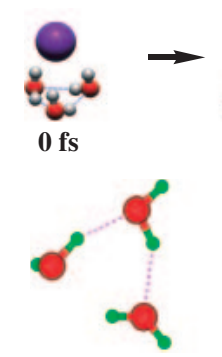

$\mathrm{EF}=0$ au

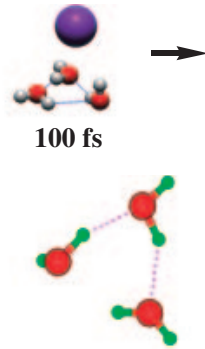

$\mathrm{EF}=0.006$ au
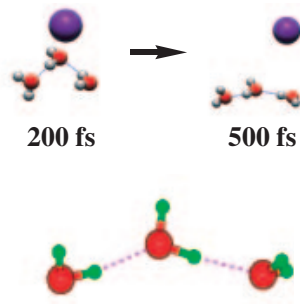

$\mathrm{EF}=0.010 \mathrm{au}$

Fig. 11. Charge-transfer-to-solvent driven structural changes of the $\left(\mathrm{H}_{2} \mathrm{O}\right)_{3} \mathrm{I}^{-}$by photo-excitation [Ref. 191] and dipole-driven structural changes of $\left(\mathrm{H}_{2} \mathrm{O}\right)_{3}$ by the applied electric field (EF) [Ref. 192].

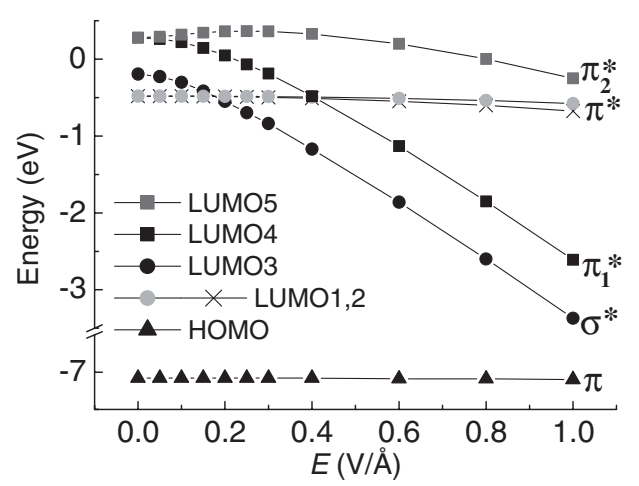

Fig. 12. Changes of HOMO-LUMO energy gap ( $E_{\text {gap }}$ in left inset) and frontier orbital energies (for $E_{\|}$in right inset) of benzene as a function of applied electric field $E$ [Ref. 193].

clophane by electrochemical and/or photochemical means leads to a very interesting model of a potential molecular device. ${ }^{189,190}$ The cyclic voltammograms exhibit two reversible redox reactions (Fig. 10). In solvents, the flapping motion driven by alternating electric field would be utilized to design a precursor of nanovehicles or nanomechanical devices.

The theoretical investigations of 1,2-bis(3-thienyl)ethene derivatives indicate that after photoswitching, the resulting $\pi$-conjugated closed forms exhibit highly non-linear optical properties. ${ }^{56}$ The substitution of suitable donors and acceptors on certain strategic positions of these ethene derivatives, however, makes the closed form optically non-linear and the resulting molecular system behaves as an efficient non-linear optical switch. It should be noted that the above discussion on non-linear optical devices involves the breaking and formation of bonds. It is interesting to explore the possibility of devices, which rely entirely on conformational or enantiomeric changes.

Electric Field Effect on Water Clusters and Benzene. Clusters such as hydrated iodide undergo the charge-transferto-solvent (CTTS) driven structural changes upon the photoexcitation (the case of $\left(\mathrm{H}_{2} \mathrm{O}\right)_{3} \mathrm{I}^{-}$in Fig. 11). ${ }^{191}$ Similarly, one can utilize electric fields to control conformational changes of molecular clusters. Using ab initio study, we investigated geometries, energies, dipole moments, and transition states of the most stable cyclic water clusters with the increasing strength of electric field. We observed that the ring opened up with the field strength more than $0.3 \mathrm{~V}^{-1}$ (for the water trimer) to align their dipole moments along the direction of the electric field, thereby forming water linear chain (Fig. 11). ${ }^{192}$ This on/off electric field results in opening/closing of the ring structure, i.e., conformational change.

Given that the electric field can change the conformation, it is conceivable to consider to change the electronic states of molecules by the electric field. Various efforts have been made toward the advancement the manipulation of molecules as molecular electronic devices. ${ }^{193}$ Our ab initio study on conducting behavior of the benzene molecule under the external electric field shows that with an increase in the applied electric field, the energy of the highly diffusive $\sigma^{*}$-type third lowest unoccupied molecular orbital (LUMO) decreases, while the $\pi$-type first and second LUMO energies are not affected (Fig. 12). Above a certain threshold of the external electric field, the third LUMO is lowered below the original LUMO and becomes the real LUMO. In the case of conductance through a single molecular orbital channel, the electric current can be selectively controlled by varying the electric field strength. This investigation shows a possible utilization of external electric fields as single molecule electronic devices.

\section{Concluding Remarks}

In this account, we have briefly discussed high-level theoretical investigations of clusters which are bound by various intermolecular interaction forces. The subtle differences in competing interaction forces and cooperative interaction forces have been very useful in the de novo design of function- 
al nanomaterials and nanodevices. We have illustrated it using several experimentally realized examples of our work on receptors with high affinity and selectivity for biologically important specific ions, organic nanotubes, metal nanowires, molecular vehicles, etc. Theoretical design provides important cues in the search for novel molecules and materials, molecular nano-electronic/mechanical devices, quantum computing devices, biomolecular sensors, and nano-surgery.

This work was supported by the GRL (KOSEF) and BK21.

\section{References}

1 U. Buck, F. Huisken, Chem. Rev. 2000, 100, 3863.

2 C. Pak, H. M. Lee, J. C. Kim, D. Kim, K. S. Kim, Struct. Chem. 2005, 16, 187.

3 P. Hobza, H. L. Selzle, E. W. Schlag, Chem. Rev. 1994, 94, 1767.

4 B. Brutschy, Chem. Rev. 2000, 100, 3891.

5 K. S. Kim, P. Tarakeshwar, J. Y. Lee, Chem. Rev. 2000, 100,4145

6 Y. W. Wang, B. H. Hong, J. Y. Lee, J.-S. Kim, G. H. Kim, K. S. Kim, J. Phys. Chem. B 2004, 108, 16723.

7 Y. W. Wang, B. H. Hong, K. S. Kim, J. Phys. Chem. B 2005, 109, 7067.

8 Y. W. Wang, J. S. Kim, G. H. Kim, K. S. Kim, Appl. Phys. Lett. 2006, 88, 143106.

9 P. Pyykkö, N. Runeberg, Angew. Chem., Int. Ed. 2002, 41, 2174.

10 J. Yoon, K. S. Kim, K. K. Baeck, J. Chem. Phys. 2000, $112,9335$.

11 M. Diefenbach, K. S. Kim, J. Phys. Chem. B 2006, 110, 21639.

12 K. S. Kim, P. Tarakeshwar, H. M. Lee, in Dekker Encyclopedia of Nanoscience, Nanotechnology, ed. by J. A. Schwarz, C. Contescu, K. Putyera, Marcel Dekker, Inc., New York, U.S.A., 2004, Vol. 3, pp. 2423-2433.

13 K. S. Kim, P. Tarakeshwar, H. M. Lee, in Theory and Applications of Computational Chemistry: The First 40 Years, ed. by C. E. Dykstra, G. Frenking, K. S. Kim, G. E. Scuseria, Elsevier, Amsterdam, Netherlands, 2005, pp. 963-993.

14 K. S. Kim, Bull. Korean Chem. Soc. 2003, 24, 757.

15 N. J. Singh, A. C. Olleta, A. Kumar, M. Park, H.-B. Yi, I. Bandyopadhyay, H. M. Lee, P. Tarakeshwar, K. S. Kim, Theor. Chem. Acc. 2006, 115, 127.

16 S. Scheiner, Hydrogen Bonding: A Theoretical Perspective, University Press, Oxford, 1997.

17 S. B. Suh, J. C. Kim, Y. C. Choi, S. Yun, K. S. Kim, J. Am. Chem. Soc. 2004, 126, 2186.

18 W. W. Cleland, M. M. Kreevoy, Science 1994, 264, 1887.

19 K. S. Kim, K. S. Oh, J. Y. Lee, Proc. Natl. Acad. Sci. U.S.A. 2000, 97, 6373 .

20 K. S. Kim, D. Kim, J. Y. Lee, P. Tarakeshwar, K. S. Oh, Biochemistry 2002, 41, 5300.

21 O. Engkvist, P. Hobza, H. L. Selzle, E. W. Schlag, J. Chem. Phys. 1999, 110, 5758.

22 P. Hobza, H. L. Selzle, E. W. Schlag, J. Am. Chem. Soc. 1994, 116, 3500 .

23 C. A. Hunter, J. K. M. Sanders, J. Am. Chem. Soc. 1990, $112,5525$.

24 C. A. Hunter, Chem. Soc. Rev. 1994, 23, 101.

25 F. Cozzi, M. Cinquini, R. Annunziata, T. Dwyer, J. S.
Siegel, J. Am. Chem. Soc. 1992, 114, 5729.

26 S. Tsuzuki, K. Honda, T. Uchimaru, M. Mikami, K. Tanabe, J. Am. Chem. Soc. 2002, 124, 104.

27 T. Sato, T. Tsuneda, K. Hirao, J. Chem. Phys. 2005, 123, 104307.

28 T. K. Manojkumar, D. Kim, K. S. Kim, J. Chem. Phys. 2005, 122, 014305 .

29 M. O. Sinnokrot, C. D. Sherrill, J. Am. Chem. Soc. 2004, 126, 7690 .

30 B. H. Hong, J. Y. Lee, S. J. Cho, S. Yun, K. S. Kim, J. Org. Chem. 1999, 64, 5661.

31 E. C. Lee, D. Kim, P. Jurečka, P. Tarakeshwar, P. Hobza,

K. S. Kim, J. Phys. Chem. A 2007, 111, 3446.

32 S. K. Burley, G. A. Petsko, Science 1985, 229, 23.

33 P. Tarakeshwar, S. J. Lee, J. Y. Lee, K. S. Kim, J. Chem. Phys. 1998, 108, 7217.

34 I. Bandyopadhyay, H. M. Lee, K. S. Kim, J. Phys. Chem. A 2005, 109, 1720.

35 T. Ren, Y. Jin, K. S. Kim, D. H. Kim, J. Biomol. Struct. Dyn. 1997, 15, 401.

36 B. H. Cardelino, C. E. Moore, D. O. Frazier, D. G. Musaev, K. Morokuma, Int. J. Quantum Chem. 1998, 66, 189.

37 K. S. Kim, J. Y. Lee, H. S. Choi, J. Kim, J. H. Jang, Chem. Phys. Lett. 1997, 265, 497.

38 P. Tarakeshwar, H. S. Choi, K. S. Kim, J. Am. Chem. Soc. 2001, 123, 3323.

39 E. C. Lee, B. H. Hong, J. Y. Lee, J. C. Kim, D. Kim, Y. Kim, P. Tarakeshwar, K. S. Kim, J. Am. Chem. Soc. 2005, 127, 4530.

40 D. A. Dougherty, D. Stauffer, Science 1990, 250, 1558.

41 R. A. Kumpf, D. A. Dougherty, Science 1993, 261, 1708.

42 J. C. Ma, D. A. Dougherty, Chem. Rev. 1997, 97, 1303.

43 J. P. Gallivan, D. A. Dougherty, J. Am. Chem. Soc. 2000, 122,870 .

44 K. S. Kim, J. Y. Lee, S. J. Lee, T.-K. Ha, D. H. Kim, J. Am. Chem. Soc. 1994, 116, 7399.

45 J. Y. Lee, S. J. Lee, H. S. Choi, S. J. Cho, K. S. Kim, T.-K. Ha, Chem. Phys. Lett. 1995, 232, 67.

46 D. Kim, S. Hu, P. Tarakeshwar, K. S. Kim, J. M. Lisy, J. Phys. Chem. A 2003, 107, 1228.

47 A. Rimola, L. Rodriguez-Santiago, M. Sodupe, J. Phys. Chem. B 2006, 110, 24189.

48 D. Kim, P. Tarakeshwar, K. S. Kim, J. Phys. Chem. A 2004, 108, 1250.

49 A. Clements, M. Lewis, J. Phys. Chem. A 2006, 2006, 110, 12705.

50 P. Gamez, J. Reedijk, Eur. J. Inorg. Chem. 2006, 29.

51 W. T. Geng, K. S. Kim, Phys. Rev. B 2003, 67, 233403.

52 Y. C. Choi, H. M. Lee, W. Y. Kim, S. K. Kwon, T. Nautiyal, D.-Y. Cheng, K. Vishwanathan, K. S. Kim, Phys. Rev. Lett. 2007, 98, 076101.

53 S. Lee, J. Kim, S. J. Lee, K. S. Kim, Phys. Rev. Lett. 1997, 79, 2038.

54 D. Majumdar, J. Kim, K. S. Kim, J. Chem. Phys. 2000, $112,101$.

55 H. M. Lee, J. Kim, C.-J. Kim, K. S. Kim, J. Chem. Phys. 2002, 116, 6549 .

56 D. Majumdar, H. M. Lee, J. Kim, K. S. Kim, B. J. Mhin, J. Chem. Phys. 1999, 111, 5866.

57 K. S. Kim, M. Dupuis, G. C. Lie, E. Clementi, Chem. Phys. Lett. 1986, 131, 451.

58 K. S. Kim, B. J. Mhin, U.-S. Choi, K. Lee, J. Chem. Phys. 
1992, 97, 6649.

59 B. J. Mhin, J. Kim, S. Lee, J. Y. Lee, K. S. Kim, J. Chem.

Phys. 1994, 100, 4484.

60 J. Kim, K. S. Kim, J. Chem. Phys. 1998, 109, 5886.

61 H. M. Lee, S. B. Suh, J. Y. Lee, P. Tarakeshwar, K. S. Kim, J. Chem. Phys. 2000, 112, 9759; 2001, 114, 3343.

62 H. M. Lee, S. B. Suh, K. S. Kim, J. Chem. Phys. 2001, 114, 10749; 2001, 115, 7331.

63 N. Pugliano, R. J. Saykally, Science 1992, 257, 1937.

64 K. Liu, M. G. Brown, J. D. Cruzan, R. J. Saykally, Science 1996, 271, 62.

65 R. N. Pribble, T. S. Zwier, Science 1994, 265, 75.

66 K. Liu, M. G. Brown, C. Carter, R. J. Saykally, J. K. Gregory, D. C. Clary, Nature 1996, 381, 501.

67 C. J. Gruenloh, J. R. Carney, C. A. Arrington, T. S. Zwier,

S. Y. Fredericks, K. D. Jordan, Science 1997, 276, 1678.

68 U. Buck, I. Ettischer, M. Melzer, V. Buch, J. Sadlej, Phys. Rev. Lett. 1998, 80, 2578.

69 K. Nauta, R. E. Miller, Science 1999, 283, 1895.

70 C. Steinbach, P. Andersson, M. Melzer, J. K. Kazimirski, U. Buck, V. Buch, Phys. Chem. Chem. Phys. 2004, 6, 3320.

71 H. M. Lee, P. Tarakeshwar, J. Park, M. R. Kołaski, Y. J. Yoon, H.-B. Yi, W. Y. Kim, K. S. Kim, J. Phys. Chem. A 2004, 108, 2949.

72 J. Kim, S. Lee, S. J. Cho, B. J. Mhin, K. S. Kim, J. Chem. Phys. 1995, 102, 839.

73 S. Lee, J. Kim, J. K. Park, K. S. Kim, J. Phys. Chem. 1996, $100,14329$.

74 H. M. Lee, J. Kim, S. Lee, B. J. Mhin, K. S. Kim, J. Chem. Phys. 1999, 111, 3995.

75 E. C. Lee, H. M. Lee, P. Tarakeshwar, K. S. Kim, J. Chem. Phys. 2003, 119, 7725.

76 H. M. Lee, S. K. Min, E. C. Lee, J.-H. Min, S. Odde, K. S. Kim, J. Chem. Phys. 2005, 122, 064314.

77 H. M. Lee, M. Diefenbach, S. B. Suh, P. Tarakeshwar, K. S. Kim, J. Chem. Phys. 2005, 123, 074328.

78 M. Kołaski, H. M. Lee, Y. C. Choi, K. S. Kim, P. Tarakeshwar, D. J. Miller, J. M. Lisy, J. Chem. Phys. 2007, 126, 074302.

79 E. D. Glendening, D. Feller, J. Phys. Chem. 1996, 100, 4790 .

80 P. Jayaweera, A. T. Blades, M. G. Ikonomou, P. Kebarle, J. Am. Chem. Soc. 1990, 112, 2452.

81 M. T. Rodgers, P. B. Armentrout, J. Phys. Chem. A 1997, $101,1238$.

82 G. Keesee, A. W. Castleman, Jr., J. Phys. Chem. Ref. Data 1986, $15,1011$.

83 J. M. Lisy, Int. Rev. Phys. Chem. 1997, 16, 267.

84 L. Lehr, M. T. Zanni, C. Frischkorn, R. Weinkauf, D. M. Neumark, Science 1999, 284, 635.

85 G. Markovich, S. Pollack, R. Giniger, O. Cheshnovsky, J. Chem. Phys. 1994, 101, 9344.

86 J.-H. Choi, K. T. Kuwata, Y.-B. Cao, M. Okumura, J. Phys. Chem. A 1998, 102, 503.

87 P. Ayotte, S. B. Nielsen, G. H. Weddle, M. A. Johnson, S. S. Xantheas, J. Phys. Chem. A 1999, 103, 10665.

88 O. M. Cabarcos, C. J. Weinheimer, J. M. Lisy, S. S. Xantheas, J. Chem. Phys. 1999, 110, 5.

89 J. Baik, J. Kim, D. Majumdar, K. S. Kim, J. Chem. Phys. 1999, 110, 9116.

90 J. Kim, H. M. Lee, S. B. Suh, D. Majumdar, K. S. Kim, J. Chem. Phys. 2000, 113, 5259.
91 H. M. Lee, K. S. Kim, J. Chem. Phys. 2001, 114, 4461.

92 H. M. Lee, D. Kim, K. S. Kim, J. Chem. Phys. 2002, 116, 5509.

93 H. M. Lee, P. Tarakeshwar, K. S. Kim, J. Chem. Phys. 2004, 121, 4657.

94 M. Miyazaki, A. Fujii, T. Ebata, N. Mikami, Science 2004, 304, 1134.

95 J.-W. Shin, N. I. Hammer, E. G. Diken, M. A. Johnson, R. S. Walters, T. D. Jaeger, M. A. Duncan, R. A. Christie, K. D. Jordan, Science 2004, 304, 1137.

96 J. M. Headrick, E. G. Diken, R. S. Walters, N. I. Hammer, R. A. Christie, J. Cui, E. M. Myshakin, M. A. Duncan, M. A. Johnson, K. D. Jordan, Science 2005, 308, 1765.

97 N. J. Singh, M. Park, S. K. Min, S. B. Suh, K. S. Kim, Angew. Chem., Int. Ed. 2006, 45, 3795; Angew. Chem. 2006, $118,3879$.

98 I. Shin, M. Park, S. K. Min, E. C. Lee, S. B. Suh, K. S. Kim, J. Chem. Phys. 2006, 125, 234305.

99 J. Kim, J. M. Park, K. S. Oh, J. Y. Lee, S. Lee, K. S. Kim, J. Chem. Phys. 1997, 106, 10207.

100 J. Kim, J. Y. Lee, K. S. Oh, J. M. Park, S. Lee, K. S. Kim, Phys. Rev. A 1999, 59, R930.

101 J. Kim, S. B. Suh, K. S. Kim, J. Chem. Phys. 1999, 111, 10077.

102 S. B. Suh, H. M. Lee, J. Kim, J. Y. Lee, K. S. Kim, J. Chem. Phys. 2000, 113, 5273.

103 H. M. Lee, S. Lee, K. S. Kim, J. Chem. Phys. 2003, 119, 187.

104 H. M. Lee, S. B. Suh, P. Tarakeshwar, K. S. Kim, J. Chem. Phys. 2005, 122, 044309.

105 N. I. Hammer, J.-W. Shin, J. M. Headrick, E. G. Diken, J. R. Roscioli, G. H. Weddle, M. A. Johnson, Science 2004, $306,675$.

106 D. H. Paik, I.-R. Lee, D.-S. Yang, J. S. Baskin, A. H. Zewail, Science 2004, 306, 672.

107 J. R. R. Verlet, A. E. Bragg, A. Kammrath, O. Cheshnovsky, D. M. Neumark, Science 2005, 307, 93.

108 J. V. Coe, G. H. Lee, J. G. Eaton, S. T. Arnold, H. W. Sarkas, K. H. Bowen, C. Ludewigt, H. Haberland, D. R. Worsnop, J. Chem. Phys. 1990, 92, 3980.

109 J. A. Kelley, G. H. Weddle, W. H. Robertson, M. A. Johnson, J. Chem. Phys. 2002, 116, 1201.

110 P. Ayotte, C. G. Bailley, J. Kim, M. A. Johnson, J. Chem. Phys. 1998, 108, 444.

111 S. Re, Y. Osamura, Y. Suzuki, H. F. Schaefer III, J. Chem. Phys. 1998, 109, 973.

112 E. M. Cabaleiro-Lago, J. M. Hermida-Ramón, J. Rodríguez-Otero, J. Chem. Phys. 2002, 117, 3160.

113 W. H. Robertson, M. A. Johnson, Science 2002, 298, 69.

114 S. Odde, B. J. Mhin, S. Lee, H. M. Lee, K. S. Kim, J. Chem. Phys. 2004, 120, 9524.

115 S. Odde, B. J. Mhin, K. H. Lee, H. M. Lee, P. Tarakeshwar, K. S. Kim, J. Phys. Chem. A 2006, 110, 7918.

116 S. Odde, C. Park, H. M. Lee, K. S. Kim, B. J. Mhin, J. Chem. Phys. 2004, 121, 204.

117 A. Veerman, H. M. Lee, K. S. Kim, J. Chem. Phys. 2005, 123,084321 .

118 A. Kumar, M. Park, J. Y. Huh, H. M. Lee, K. S. Kim, J. Phys. Chem. A 2006, 110, 12484.

119 A. C. Olleta, H. M. Lee, K. S. Kim, J. Chem. Phys. 2006, $124,024321$.

120 N. J. Singh, H.-B. Yi, S. K. Min, M. Park, K. S. Kim, 
J. Phys. Chem. B 2006, 110, 3808.

121 O. Höfft, U. Kahnert, S. Bahr, V. Kempter, J. Phys. Chem. B 2006, 110, 17115.

122 A. Borodin, O. Höfft, V. Kempter, J. Phys. Chem. B 2005, 109, 16017.

123 A. Borodin, O. Höfft, S. Krischok, V. Kempter, J. Phys. Chem. B 2003, 107, 9357.

124 P. Tarakeshwar, K. S. Kim, E. Kraka, D. Cremer, J. Chem. Phys. 2001, 115, 6018.

125 J. Y. Lee, J. Kim, H. M. Lee, P. Tarakeshwar, K. S. Kim, J. Chem. Phys. 2000, 113, 6160.

126 J. D. Augspurger, C. E. Dykstra, T. S. Zwier, J. Phys. Chem. 1992, 96, 7252 .

127 P. Tarakeshwar, J. Y. Lee, K. S. Kim, J. Phys. Chem. A 1998, 102, 2253.

128 P. Tarakeshwar, S. J. Lee, J. Y. Lee, K. S. Kim, J. Phys. Chem. B 1999, 103, 184.

129 P. Tarakeshwar, K. S. Kim, J. Phys. Chem. A 1999, 103, 9116.

130 G. A. Olah, B. Török, J. P. Joschek, I. Bucsi, P. M. Esteves, G. Rasul, G. K. S. Prakash, J. Am. Chem. Soc. 2002, 124, 11379. 131 M. J. Earle, K. R. Seddon, Pure Appl. Chem. 2000, 72, 1391.

132 J. R. Grover, E. A. Walters, E. T. Hui, J. Phys. Chem. 1987, 91, 3233.

133 H. Krause, B. Ernstberger, H. J. Neusser, Chem. Phys. Lett. 1991, 184, 411.

134 A. Kiermeier, B. Ernstberger, H. J. Neusser, E. W. Schlag, J. Phys. Chem. 1988, 92, 3785.

135 E. Arunan, H. S. Gutowsky, J. Chem. Phys. 1993, 98, 4294.

136 H. M. Lee, M. Ge, B. R. Sahu, P. Tarakeshwar, K. S. Kim, J. Phys. Chem. B 2003, 107, 9994.

137 K. S. Kim, J. M. Park, J. Kim, S. B. Suh, P. Tarakeshwar, K. H. Lee, S. S. Park, Phys. Rev. Lett. 2000, 84, 2425.

138 Y. Rikiishi, Y. Kashino, H. Kusai, Y. Takabayashi, E. Kuwahara, Y. Kubozono, T. Kambe, T. Takenobu, Y. Iwasa, N. Mizorogi, S. Nagase, S. Okada, Phys. Rev. B 2005, 71, 224118.

139 M. Yamada, T. Nakahodo, T. Wakahara, T. Tsuchiya, Y. Maeda, T. Akasaka, M. Kako, K. Yoza, E. Horn, N. Mizorogi, K. Kobayashi, S. Nagase, J. Am. Chem. Soc. 2005, 127, 14570.

140 J. M. Park, P. Tarakeshwar, K. S. Kim, T. Clark, J. Chem. Phys. 2002, 116, 10684.

141 Endofullerenes: A New Family of Carbon Clusters, ed. by T. Akasaka, S. Nagase, Kluwer, Dordrecht, 2002.

142 H. S. Choi, K. S. Kim, Angew. Chem., Int. Ed. 1999, 38, 2256; Angew. Chem. 1999, 111, 2400.

143 B. H. Hong, J. P. Small, M. S. Purewal, A. Mullokandov, M. Y. Sfeir, F. Wang, J. Y. Lee, T. F. Heinz, L. E. Brus, P. Kim, K. S. Kim, Proc. Natl. Acad. Sci. U.S.A. 2005, 102, 14155.

144 B. H. Hong, J. Y. Lee, T. Beetz, Y. Zhu, P. Kim, K. S. Kim, J. Am. Chem. Soc. 2005, 127, 15336.

145 D.-H. Oh, J. M. Park, K. S. Kim, Phys. Rev. B 2000, 62 , 1600.

146 J. A. Rodríguez-Manzo, F. López-Urías, M. Terrones, H. Terrones, Nano Lett. 2004, 4, 2179.

147 C. G. Rocha, M. Pacheco, Z. Barticevic, A. Latgé, Phys. Rev. B 2004, 70, 233402.

148 T. R. Kline, M. L. Tian, J. Wang, A. Sen, M. W. H. Chan, T. E. Mallouk, Inorg. Chem. 2006, 45, 7555.

149 A. Rogachev, A. Bezryadin, Appl. Phys. Lett. 2003, 183,512
150 M. P. Zach, K. Inazu, K. H. Ng, J. C. Hemminger, R. M. Penner, Chem. Mater. 2002, 14, 3206.

151 A. Nakamura, K. Matsunaga, T. Yamamoto, Y. Ikuhara, Appl. Surf. Sci. 2005, 241, 38.

152 V. Rodrigues, J. Bettini, P. C. Silva, D. Ugarte, Phys. Rev. Lett. 2003, 91, 096801.

153 A. Bala, T. Nautiyal, K. S. Kim, Phys. Rev. B 2006, 74, 174429.

154 T. Nautiyal, S. J. Youn, K. S. Kim, Phys. Rev. B 2003, 68, 033407.

155 T. Nautiyal, T. H. Rho, K. S. Kim, Phys. Rev. B 2004, 69, 193404.

156 W. Y. Kim, T. Nautiyal, S. J. Youn, K. S. Kim, Phys. Rev. B 2005, 71, 113104.

157 D. Cheng, W. Y. Kim, S. K. Min, T. Nautiyal, K. S. Kim, Phys. Rev. Lett. 2006, 96, 096104.

158 Supramolecular Chemistry, ed. by J. M. Lehn, VCH Press, Weinheim, Germany, 1995.

159 J.-S. Wu, I.-C. Hwang, K. S. Kim, J. S. Kim, Org. Lett. 2007, 9, 907.

160 C. J. Pedersen, J. Am. Chem. Soc. 1967, 89, 7017.

161 K. S. Oh, C.-W. Lee, H. S. Choi, S. J. Lee, K. S. Kim, Org. Lett. 2000, 2, 2679.

162 S. Yun, Y.-O. Kim, D. Kim, H. G. Kim, H. Ihm, J. K. Kim, C.-W. Lee, W. J. Lee, J. Yoon, K. S. Oh, J. Yoon, S.-M. Park, K. S. Kim, Org. Lett. 2003, 5, 471.

163 J. Yoon, S. K. Kim, N. J. Singh, K. S. Kim, Chem. Soc. Rev. 2006, 35, 355.

164 L. Fabbrizzi, A. Poggi, Chem. Soc. Rev. 1995, 24, 197.

165 F. P. Schmidtchen, M. Berger, Chem. Rev. 1997, 97, 1609.

166 N. J. Singh, E. J. Jun, K. Chellappan, D. Thangadurai, R. P. Chandran, I.-C. Hwang, J. Yoon, K. S. Kim, Org. Lett. 2007, 9, 485 .

167 H. N. Lee, N. J. Singh, S. K. Kim, J. Y. Kwon, Y. Y. Kim, K. S. Kim, J. Yoon, Tetrahedron Lett. 2007, 48, 169.

168 J. L. Sessler, S. Camiolo, P. A. Gale, Coord. Chem. Rev. 2003, 240, 17.

169 P. A. Gale, R. Quesada, Coord. Chem. Rev. 2006, 250, 3219.

170 R. Martínez-Máñez, F. Sancenón, Chem. Rev. 2003, 103, 4419.

171 H. Ihm, S. Yun, H. G. Kim, J. K. Kim, K. S. Kim, Org. Lett. 2002, 4, 2897.

172 S. Yun, H. Ihm, H. G. Kim, C.-W. Lee, B. Indrajit, K. S. Oh, Y. J. Gong, J. W. Lee, J. Yoon, H. C. Lee, K. S. Kim, J. Org. Chem. 2003, 68, 2467.

173 S. K. Kim, N. J. Singh, S. J. Kim, H. G. Kim, J. K. Kim, J. W. Lee, K. S. Kim, J. Yoon, Org. Lett. 2003, 5, 2083.

174 J. Yoon, S. K. Kim, N. J. Singh, J. W. Lee, Y. J. Yang, K. Chellappan, K. S. Kim, J. Org. Chem. 2004, 69, 581.

175 S. K. Kim, N. J. Singh, S. J. Kim, K. M. K. Swamy, S. H. Kim, K. H. Lee, K. S. Kim, J. Yoon, Tetrahedron 2005, 61, 4545. 176 S. K. Kim, N. J. Singh, J. Kwon, I.-C. Hwang, S. J. Park, K. S. Kim, J. Yoon, Tetrahedron 2006, 62, 6065.

177 H. N. Lee, N. J. Singh, S. K. Kim, J. Y. Kwon, Y. Y. Kim, K. S. Kim, J. Yoon, Tetrahedron Lett. 2007, 48, 169.

178 J. Y. Kwon, N. J. Singh, H. N. Kim, S. K. Kim, K. S. Kim, J. Yoon, J. Am. Chem. Soc. 2004, 126, 8892.

179 N. J. Singh, E. J. Jun, K. Chellappan, D. Thangadurai, R. P. Chandran, I.-C. Hwang, J. Yoon, K. S. Kim, Org. Lett. 2007, 9, 485.

180 K. Chellapan, N. J. Singh, I.-C. Hwang, J. W. Lee, K. S. 
Kim, Angew. Chem., Int. Ed. 2005, 44, 2899; Angew. Chem. 2005, 117, 2959.

181 H. S. Choi, S. B. Suh, S. J. Cho, K. S. Kim, Proc. Natl. Acad. Sci. U.S.A. 1998, 95, 12094.

182 H. S. Choi, D. Kim, P. Tarakeshwar, S. B. Suh, K. S. Kim, J. Org. Chem. 2002, 67, 1848.

183 H. Huang, L. Mu, J. He, J.-P. Cheng, Tetrahedron Lett. 2002, 43, 2255 .

184 J. Y. Lee, S. K. Kim, J. H. Jung, J. S. Kim, J. Org. Chem. 2005, 70, 1463.

185 B. H. Hong, J. Y. Lee, C.-W. Lee, J. C. Kim, S. C. Bae, K. S. Kim, J. Am. Chem. Soc. 2001, 123, 10748.

186 B. H. Hong, S. C. Bae, C.-W. Lee, S. Jeong, K. S. Kim, Science 2001, 294, 348.

187 K. S. Kim, S. B. Suh, J. C. Kim, B. H. Hong, E. C. Lee, S. Yun, P. Tarakeshwar, J. Y. Lee, Y. Kim, H. Ihm, H. G. Kim, J. W.
Lee, J. K. Kim, H. M. Lee, D. Kim, C. Cui, S. J. Youn, H. Y. Chung, H. S. Choi, C.-W. Lee, S. J. Cho, S. Jeong, J.-H. Cho, J. Am. Chem. Soc. 2002, 124, 14268.

188 H.-B. Yi, M. Diefenbach, Y. C. Choi, E. C. Lee, H. M. Lee, B. H. Hong, K. S. Kim, Chem. Eur. J. 2006, 12, 4885.

189 H. G. Kim, C.-W. Lee, S. Yun, B. H. Hong, Y.-O. Kim, D. Kim, H. Ihm, J. W. Lee, E. C. Lee, P. Tarakeshwar, S.-M. Park, K. S. Kim, Org. Lett. 2002, 4, 3971.

190 T. K. Manojkumar, H. S. Choi, B. H. Hong, P. Tarakeshwar, K. S. Kim, J. Chem. Phys. 2004, 121, 841.

191 M. Kołaski, H. M. Lee, C. Pak, M. Dupuis, K. S. Kim, J. Phys. Chem. A 2005, 109, 9419.

192 Y. C. Choi, C. Pak, K. S. Kim, J. Chem. Phys. 2006, 124, 094308.

193 Y. C. Choi, W. Y. Kim, K.-S. Park, P. Tarakeshwar, K. S. Kim, T.-S. Kim, J. Y. Lee, J. Chem. Phys. 2005, 122, 094706.
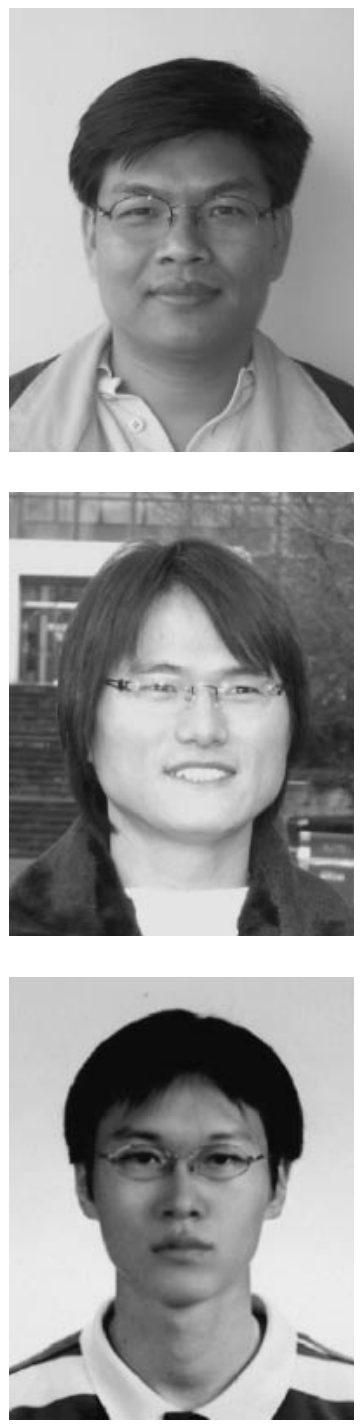

N. Jiten Singh was born in Kakching (INDIA) in 1971. In 1994 and 1997, he received his M.Sc. and M.Tech. from IIT Kanpur and IIT Delhi, respectively. During 1997-2002, he worked in R\&D center of Torrent Pharmaceutical Ltd. as a computer-aided-drug-designer. He received his Ph.D. degree in 2006 from Pohang University of Science and Technology (POSTECH) under the guidance of Prof. Kwang S. Kim. His research interests include investigating the non-bonding interactions in ion receptors, molecular clusters, and protein-drug complexes.

Eun Cheol Lee was born in Chungju (Korea) in 1975. He received his B.S. degree from Kanwon National University and M.S. degree from Pohang University of Science and Technology $(\mathrm{POSTECH})$ in the field of Chemistry. He is a Ph.D. candidate working with K. S. Kim at POSTECH. His research interests include the intermolecular interaction in $\pi$ systems.

Young Cheol Choi received his B.S. degree from Pohang University of Science and Technology (POSTECH). He is a Ph.D. candidate working with K. S. Kim at POSTECH. His research interests include the electric field effect on electronic structures and spectroscopic properties of various chemical systems including metallic nanowires. 

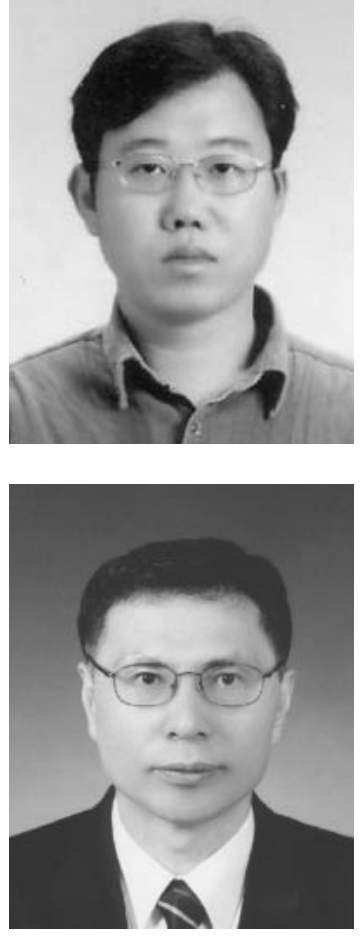

Han Myoung Lee was born in Jeonbuk in 1969. He graduated from WonKwang University in 1991. He received his master degree in 1993 and Ph.D. degree in 1997 both from WonKwang University under the direction of Prof. Kee Hag Lee. He was a postdoctoral fellow in Professor Kwang Soo Kim's group at Pohang University of Science and Technology from 1997 to 2000. Now he is an assistant research professor at Pohang University of Science and Technology. His research interests are cluster science, photo dynamics, and so on.

Kwang S. Kim was born in Seoul in 1950. He received his Ph.D. degree from the University of California, Berkeley, working with H. F. Schaefer, III. After spending a few years as an IBM postdoctoral fellow with E. Clementi and as a research assistant professor at Rutgers University, he joined Pohang University of Science and Technology. He is currently a professor and the director of the Center for Superfunctional Materials. His research interests include investigations of molecular recognition, receptors, drugs, biomolecules, nanomaterials, and molecular devices. 